ISSN 1112-9867

\title{
VALORIZATIONS ENVIRONMENTAL, ENERGY AND AGRONOMIC OF BIOMETHANISATION INDUSTRIAL OF THE AVICOLOUS BIOMASS
}

\author{
Y. M'Sadak* and A. Ben M'Barek
}

Department of the Genius of the Horticultural Systems and the Natural Environment Higher Agronomic Institute of Chott-Mariem, University of Sousse, Tunisia

Received: 20 March 2014 / Accepted: 28 December 2014 / Published online: 15 January 2015

\begin{abstract}
This work consists in studying the anaerobie fermentation of the avicolous droppings on the level a digester pilot industrial. It was interested towards substitution partial of Forestry Compost (FC), produces locally in one seedbed except ground, by the avicolous methacompost refined in its two states, namely at the exit of decanter (AMCA) and at the exit of digester (AMCA') according one rate of $20 \%$. The synthesis of the principal results is: the best assessments of depollution are obtained on the level of the mud tank as well concerning $\mathrm{SM}$ and $\mathrm{DBO}_{5}$; the incorporation of the avicolous methacompost with $\mathrm{FC}$ has a remarkable positive effect on germination, and consequently, on the growth of the seedlings of Acacia cyanophylla, in terms of height and of diameter; the best results of growth in height and diameter correspond to the mixture $80 \% \mathrm{FC}+20 \%$ AMCA'.
\end{abstract}

KEYWORDS: Biomethanisation industrial avicolous ; assessments of depollution ; gas composition ; calorific value ; methacompost avicolous ; substrate of culture.

\section{INTRODUCTION}

The governments are constantly in search of a technological allowing effective cure and less expensive solutions waste. One of technologies allowing the treatment of the organic fraction of this waste is the biomethanisation which can transform a problem of waste into a source of richnesses [1].

Author Correspondence, e-mail: msadak.youssef@yahoo.fr

Tel.: +21673 327 544; fax: +21673327 591 .

ICID: 1124400 
There exists, indeed, several recycling appropriatenesses of organic waste, in particular for and the fertilization energy production of agricultural land, so as to reduce the quantity of buried organic waste and to diversify the energy sources of substitution.

The animal manure is particularly interesting to use when they are produced in significant amounts and regular [2] and especially when they are treated by biomethanisation before use $[3,4]$.

Alkaline fermentation is, today, the bioenergetic die with the most promising prospects $[5,6]$. Its industrial application, after progress of the last years of research, starts to become a reality. Indeed, the techniques available are right now sufficiently powerful to return the systems proposed economically acceptable [7].

The degradation of MO by anaerobic way is recognized more and more like fundamental method of advanced technology allowing environmental protection and the conservation of the resources [8-10]. The good performance (depollution, energy potentiality) of this kind of process is largely conditioned by the physicochemical conditions (nature, $\mathrm{pH}, \mathrm{DM} \ldots$ ) substrates implemented.

The present study aims primarily a performance evaluation environmental and energy of the digester controls industrial (supplied with poultry droppings) installed in Hammam Sousse, while limiting themselves to a restricted physicochemical follow-up and to the determination of its assessment of depollution (Suspended Matter: SM and Asks Biological out of Oxygen: $\mathrm{DBO}_{5}$ ) and of its qualitative productivity of biogas (Composition in Biomethane: $\mathrm{CH}_{4}$ and Calorific Value: CV). It also rests on a determination of principal possible interventions on the level of the installation for a better production and an optimal valorization of the byproducts of the biomethanisation (biogas and digestats).

The agronomic use of the residues of the biomethanisation is integrated well in the current trend towards the agrobiologic practices, taking into account the important reduction of the polluting load of the dejections after biological treatment. Concerning the digestat (secondary by-product of the biomethanisation), the use particularly of its solid fraction called methacompost, like substitute partial of Forestry Compost (FC) considered as substrate of reference for the production of the forest seedlings, could constitute an interesting alternative to improve its chemical quality especially, and consequently, the quality of the produced forest seedlings.

This work is directed primarily towards the focusing of the substrates of growth containing mixture of compost and methacompost avicolous (AMC), adequate for the production except 
ground of the forest seedlings. In addition, an indirect evaluation was undertaken, primarily aiming the appreciation of the germination of the seeds and the growth in height and diameter, of the seedlings of Acacia cyanophylla installed, on the one hand, on the FC alone in a pure state, and on the other hand, on the FC mixed with the AMC in its two states in its two states, namely at the exit of the decanter (AMCA) and at the exit of digester (AMCA') according to the same ratio, at a rate of $20 \%$ in each mixture.

The two made mixtures which are revealed the best following the direct evaluation of the physicochemical properties of various substrates made starting from various combinations of the FC with the AMCA or the AMCA'.

\section{MATERIALS AND METHODS}

\subsection{EXPERIMENTAL DEVICE}

\subsubsection{TECHNICAL PRESENTATION OF THE STUDIED DIGESTER}

It is about a pilot digester of cylindrical form, installed in a poultry farm since the year 2000 , of a service output of $300 \mathrm{~m}^{3}$, fed uninterrupted daily by $10 \mathrm{~m}^{3}$ of substrate made up from approximately $1 / 3$ of avicolous droppings and $2 / 3$ of water.

The quantities of droppings available represent the day laborer production of an avicolous breeding out of cages around 20000 layers. The installation is designed to treat 4 tons of fresh dejections daily and to produce $200 \mathrm{~m}^{3}$ biogas/day which can be transformed into $300 \mathrm{kWh}$ electric of which 5 to $10 \%$ only are currently consumed by owner [11] to feed from the generators and to thus satisfy the needs for the farm and the station in electrical energy.

Besides the energy objective, the unit of biomethanisation has an environmental objective which consists in reducing the pollution generated by the droppings.

\subsubsection{CiRCUITS OF THE AVICOLOUS DROPPINGS}

In the digester, the produced digested droppings cross three different basins: a first basin receiving the substrate digested for a weak residence time (called basin of the digested droppings) before remaining in the second basin called decanter or mud tank. Starting from this last, muds of the elutriated droppings will be dried and transformed into methacompost. As for water supernatant (Juice of process) the mud tank, it passes in the third basin to be used for scraping of the fresh droppings of the hen houses.

\subsection{ANALYTICAL FOLLOW-UP}

\subsubsection{General Considerations}


The follow-up related to several physicochemical, environmental and energy parameters for one variable period between one to four weeks according to raised performances of digestion. The physicochemical and environmental analyzes were carried out at the laboratory "Biogas" of the Agricultural Professional training center in Bovine Breeding (CFPAEB) of Sidi Thabet, Tunisia.

Samplings of the avicolous droppings were made at three various points of the installation (basins of before and according to fermentation and tank mud) corresponding successively to three phases of the process of fermentation: front, with the course and after digestion, and this in order to establish the assessments of evolution of certain physicochemical parameters studied all the way along the experimentation, as well as the assessments of depollution. Moreover, one taking away of the droppings fraiches was carried out starting from a hen house in order to appreciate the initial moisture of the droppings before scraping.

As for the biogas qualitative analyzes, they were carried out at the test laboratories concerned with the Tunisian Company of Industries of Refining (STIR) of Bizerte.

The taking away of biogas were carried out before and after purification in order to appreciate the importance of the purification (desulphurization) of the biogas produced with respect to the energy potentialities (\% methane, calorific value).

\subsubsection{PhysicocheMical PARAMETERS}

The physicochemical parameters tested were limited to:

\subsubsection{1 $\mathrm{pH}$}

The $\mathrm{pH}$ constitutes a total measure of the hydrogen ions using a pH-meter. It is admitted that the $\mathrm{pH}$ is the first indicator of the faulty possible operation of a digester. Anaerobic digestion proceeds in an optimal way in the vicinity of neutrality $(\mathrm{pH} 7.2 \pm 0.5)$. But, it is generally possible between $\mathrm{pH} 5$ and $\mathrm{pH}$ 9. A fall of $\mathrm{pH}$ increases the content of Fatty-acids Volatile (AGV), not ionized, and consequently, the phenomena of inhibition on the micro-organisms [7].

\subsubsection{DRY MATTER RATE}

The Dry Matter rate (DM) is the rate complementary to the percentage of moisture. It is thus a question of determining the degree or content water and the percentage of water in the matter using a drying with the drying oven.

\subsubsection{ENVIRONMENTAL PARAMETERS}

The environmental follow-up was limited to the two parameters hereafter:

\subsubsection{SUSPENDED MATTER}


The Suspended Matter (SM) gathers the matters of which the density is lower than the density of water. They correspond to the whole of mineral and/or organic particles present in a natural or polluted water [12]. The estimate of this parameter calls upon three stages: filtration, drying and weighing.

\subsubsection{BIOLOGICAL DEMAND FOR OXYGEN}

The Biological Request Oxygenates some $\left(\mathrm{DBO}_{5}\right)$ constitutes a good indicator of the $\mathrm{MO}$ content biodegradable of a water (any biodegradable MO polluting involves an oxygen uptake) during processes of self-purification. The principle of the measurement of the $\mathrm{DBO}_{5}$ rests on the $\mathrm{O}_{2}$ quantification consumed after incubation of the sample during 5 days.

\subsubsection{QUALITATIVE FOLLOW-UP OF THE GAS PRODUCTIVITY}

The evaluation of the gas productivity imposes the quantitative and qualitative follow-up gas produced on the level of the industrial digester. Following the dysfunction of the flowmeter installed, the quantitative follow-up could not be carried out and one limited oneself only to the qualitative follow-up which related to biogas taken, once flammable by determining its gas composition and its calorific value.

\subsubsection{COMPOSITION IN GAS ELEMENTS}

The quality of biogas is evaluated primarily by the measurement of $\%$ methane $\left(\mathrm{CH}_{4}\right)$ which it contains. Indeed, a biogas is of as much better than its \% methane is high. But, it also rests on the determination of \% carbon dioxide $\left(\mathrm{CO}_{2}\right), \%$ sulphurizes hydrogen $\left(\mathrm{H}_{2} \mathrm{~S}\right)$ and \% hydrogen $\left(\mathrm{H}_{2}\right)$. In opposition to methane, plus \% of these elements are reduced, plus the quality of produced biogas is better.

\subsubsection{CALORIFIC VALUE}

The calorific value of a fuel is the quantity of heat released by the complete combustion of 1 Normal $\mathrm{m}^{3}$ of dry gas (quantity of gas matter which $1 \mathrm{~m}^{3}$ under the normal conditions of temperature and pressure occupies: $0^{\circ} \mathrm{C}$ under 1 Atmosphere) in the air with a constant absolute pressure. It is a question of evaluating the Lower Calorific value (PCI) and the Higher Calorific value (PCS) expressed in $\left(\mathrm{kcal} / \mathrm{Nm}^{3}\right)$ and bound by relation 1 following:

$$
\mathrm{HCV}=\mathrm{LCV}+\text { heat of vaporization }
$$

The NCV is calculated energy when the water produced by this combustion remains with the vapor state. According to [13], the calorific value of biogas is proportional to its content of $\mathrm{CH}_{4}$. It varies between 5000 and $8500 \mathrm{kcal} / \mathrm{Nm}^{3}$. 
The water formed during combustion is brought back in the liquid state, the other products being with the gas state. Thus, the latent heat of vaporization is that necessary to transform $1 \mathrm{~kg}$ water into vapor.

\subsection{POSSIBILITIES OF AGRONOMIC VALORIZATION EXCEPT GROUND OF THE AVICOLOUS METHACOMPOST}

\subsubsection{VEGETABLE MATERIAL}

A leafy forest species with rapid growth, Acacia cyanophylla, was used to study the vegetable answer with respect to various substrates of growth tested. The seeds of this species were provided by the Head office of Forests (DGF), and were collected starting from shrubs located in the area of Enfidha, Sousse (Tunisia).

\subsubsection{SUBSTRATES OF CULTURE}

The made substrates, object of this study, are obtained following the mixture of pure compost of vegetable origin with a methacompost of animal origin.

The green woody biomass, in the form of branches of Acacia cyanophylla, was used to produce a compost with the characteristics necessary for the breeding of forest seedlings in seedbed modern $[14,15]$. The compost of produced Acacia constituted the basic matrix in the preparation of the substrates of culture tested.

The pure substrates are the following:

- Forestry Compost, (FC) produced Gross in the modern forest seedbed of Chott-Mariem, Sousse. It is resulting from the branches of Acacia cyanophylla crushed successively by a simple knife crusher and a simple hammer crusher equipped with a grid of calibration of mesh $30 \mathrm{~mm}$.

- Avicolous Methacompost (AMC), solid residue resulting from a unit of industrial biomethanisation in Hammam Sousse) in its two states, namely at the exit of decanter (AMCA) and at the exit of digester (AMCA') according to the same ratio of mixture, at a rate of $20 \%$.

The evaluated substrates are three:

SA: Standard substrate FC (pilot)

SB: Mix $80 \%$ FC $+20 \%$ AMCA

SC: Mix $80 \%$ FC + 20\% AMCA'

The two made mixtures appeared the best, following the direct evaluation of the physicochemical properties of various mixtures made starting from three pure components considered. 


\subsubsection{AgRONOMIC FOLLOW-UPS}

\subsubsection{TEST OF GERMINATION ON LEGUMINOUS PLANTS}

The goal of the biotest is to evaluate the maturity of the methacompost, to envisage the possible existence of some elements phytotoxic, while putting in consideration the photosensitivity of the seeds of Plant-tests [16]. For the appreciation of the maturity of the FC, one used two leguminous plants: the bean and the chick-pea. The bean translates the phytotoxicity by a yellowing of the sheets and a depressed growth, even null. Pea-Chiche is selected because of its prompt response.

This biotest studies germination and the growth during 28 days [17, 18] of the plant-tests cultivated out of containers filled of the FC produced with the seedbed. For each plant specie, one used 4 containers (either 15 cavities X 4 containers X 2 species $=120$ plant-tests). The biotest touched only the FC, since the AMC studied on the outlet side of the digester or decanter is already ripe. The measured parameters are the duration of germination and the percentage of germination.

\subsubsection{EVAlUATION OF THE BEHAVIOR OF THE SEEDLINGS OF ACACIA}

To appreciate the vegetative behavior of the seedlings considered, one was satisfied to follow the evolution of morphological parameters hereafter.

- Percentage of germination of the seeds of Acacia: Measurements of germination were taken one week after sowing, while ensuring counting cumulated every 4 days.

- Increase in height in seedlings: The follow-up of the evolution of the air part of the seedlings was led starting from the measurements in $\mathrm{cm}$ (with 15 days more or less regular intervals) since the collet to the apical bud using a digital slide caliper.

- Increase in diameter in seedlings: The measurements in mm were taken at the same time as those of the increase in height and with the same material.

It should be noted that, for each container, one chose 5 seedlings ( 5 seedlings container, a seedling 3 cavities) to by chance take measurements in height and diameter. These same seedlings were used for all the statements as growth.

- Ratio of robustness of the seedlings: It is equal to the Height ratio/Diamètre (H/D), expressed in $\mathrm{cm} / \mathrm{mm}$.

The experimental device implemented calls upon a plan in complete random blocks (BAC) with a studied factor ( 3 substrates) and a controlled factor ( 3 blocks). They are 18 containers (5 X 3 cavities/container) distributed as follows: 2 containers X 3 substrates X 3 blocks.

\section{RESULTS AND DISCUSSION}




\subsection{FOLLOW-UP OF CERTAIN PHYSICOCHEMICAL CONDITIONS}

\subsubsection{EVOLUTION OF THE PH}

Figure 1 shows the fluctuations of the $\mathrm{pH}$, measured only once, during the process of fermentation alkaline.

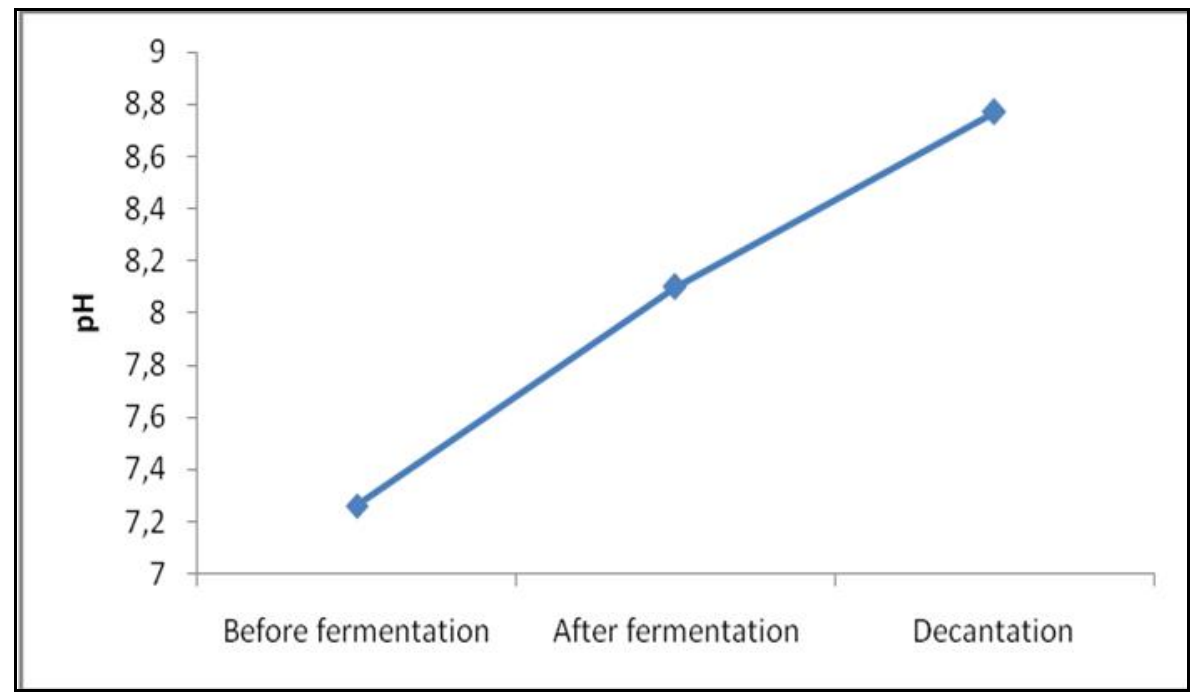

Fig. 1. Evolution of the $\mathrm{pH}$ during the process of biomethanisation

The basin of mixture or basin of before fermentation, has a $\mathrm{pH}$ from approximately 7.2 as for the two basins according to fermentation, they present rather high values which vary from a $\mathrm{pH}$ of 8 , in the first basin receiving the digested droppings, with an equal rather alkaline $\mathrm{pH}$ 8.8 in the mud tank.

Only the actual value of the $\mathrm{pH}$ on the level of the basin of mixture is in conformity with recommendations $(\mathrm{pH} 7.2 \pm 0.5)$. For the other basins, they are arranged with the free air and their exposure to the climatic risks (in particular, rains) could be at the origin of the remarkable variations of the $\mathrm{pH}$.

\subsubsection{EVOLUTION OF THE MATTER DRIES}

According to the theory, the concentration in Matter Dries (DM) of the poultry droppings in a digester should not exceed $10 \%$. Beyond this value, the matter is dense and causes the methane arrested fermentation quickly [19].

The variation of $\% \mathrm{DM}$ at different points from the installation is represented by figure 2 . 


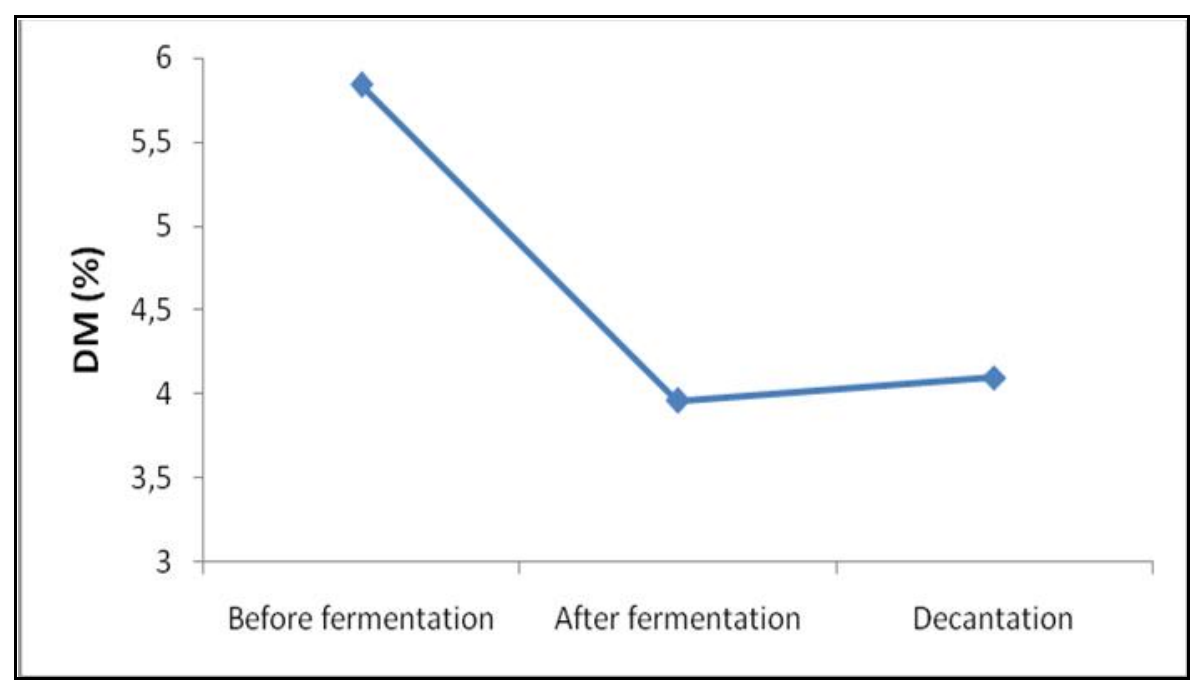

Fig. 2. Evolution of the DM at various levels of the installation

The adjustment of \% DM to a value lower than $10 \%$ is a paramount and very demanding stage for a better course of the process of fermentation since the fresh avicolous droppings have at the beginning a rate of ms equal to $20,9 \%$. The scraping of this droppings with the juice of process makes it possible to dilute them to obtain a rate of $\mathrm{ms}$ in the neighborhoods of $6 \%$ Juste before fermentation. The circulation of the scraped droppings and its mixture with the droppings already respectively digested and elutriated in the other basins makes it possible to reduce this rate of ms more. The fall of the rate of $\mathrm{ms}$ could be also explained by the degradation of MO by the micro-organisms during fermentation.

After digestion, there do not exist clear differences between the values recorded in the basin of the digested droppings and the decanter. A weak increase of about $0.2 \%$ is recorded on the level of the decanter.

\subsection{ESTABLISHMENT OF THE ASSESSMENTS OF DEPOLLUTION}

\subsubsection{ReSUlts RELATING TO THE SUSPENDED MATter}

The evolution of the rate as of Suspended Matter (SM) during various phases of fermentation is described by the curve represented on figure 3.

SM are in continuous decrease throughout the advance of the substrate, which could be explained by the good biological breakdown of MO (a reduction higher than $80 \%$ as of SM on the level of the mud tank). This biological breakdown is largely due to the practiced system of digestion, with fixed cells, calling upon 6000 bricks of 12 laid out in superposition and which allows a good retention of the bacteria methanogenes inside the digester. 


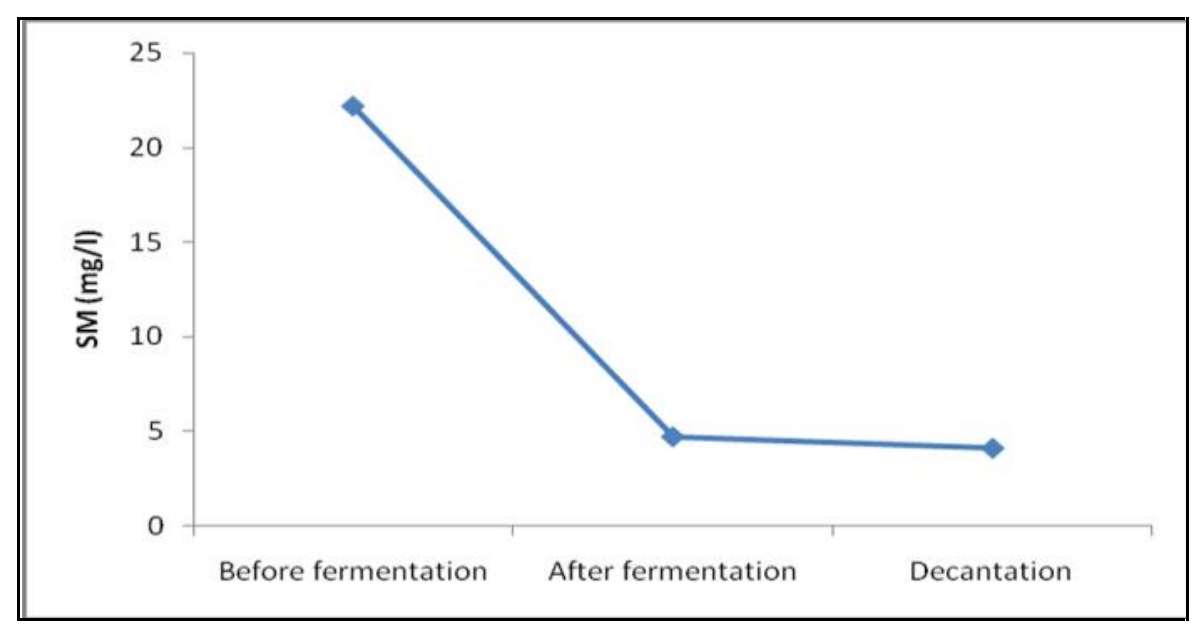

Fig. 3. Evolution as of SM during fermentation

\subsubsection{RESUlTS RELATING TO THE DBO5}

Figure 4 shows the variation of the values of the $\mathrm{DBO}_{5}$ during various phases of biomethanisation.

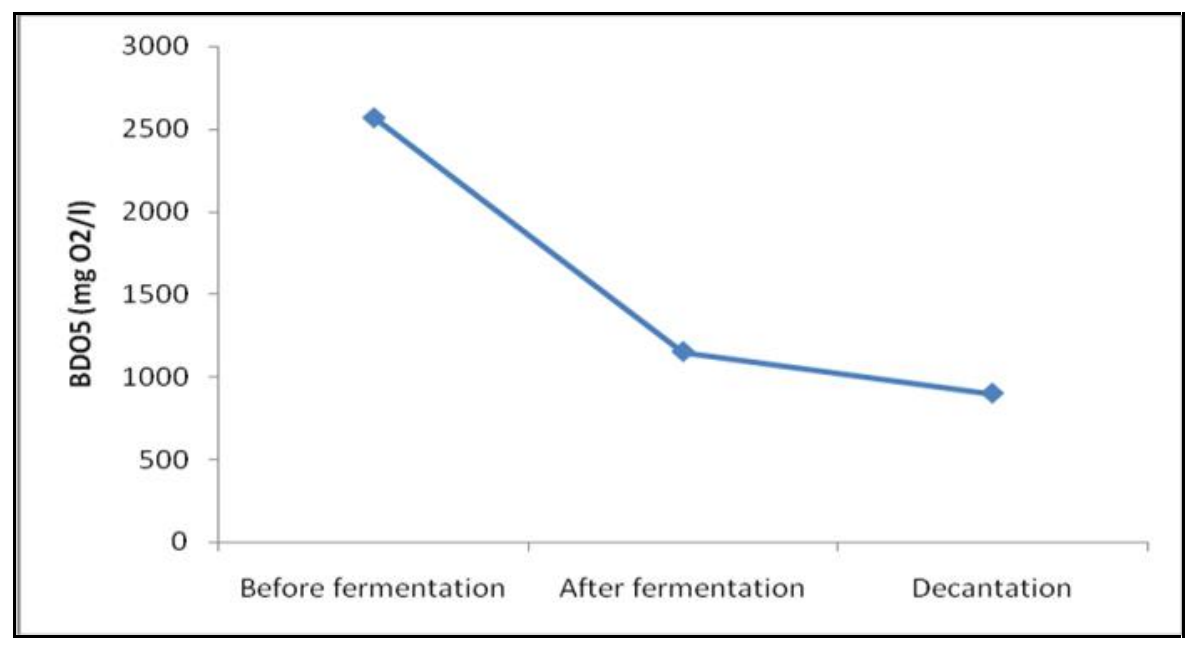

Fig. 4. Evolution of the $\mathrm{DBO}_{5}$ during fermentation

The curve of space-time evolution of the $\mathrm{DBO}_{5}$ is practically superposable with that of SM, which makes it possible to release the same observations. The corresponding results show a reduction of the polluting load exceeding $55 \%$ in both cases. This potentiality is accentuated on the level of the mud tank with a difference of about $6 \%$ compared to the basin of the digested droppings. The decantation of the digested matter thus supports the reduction of the polluting load. With the result that this stage is very interesting and the results are encouraging to give more importance to the maintenance in operating condition of the mud tank. 


\subsection{ESTABLISHMENT OF THE ASSESSMENTS OF PURIFICATION}

The biogas produced by the industrial digester undergoes purification by calling upon a desulphurization with the iron hematite. In this respect, the follow-up was carried out before and after purification to appreciate the interest of this treatment. The performance evaluation of conditioning carried out is interpreted starting from the results of analysis of the composition of biogas and its calorific value.

\subsubsection{EFFECT OF PURIFICATION ON THE COMPOSITION OF PRODUCED BIOGAS}

Table 1 illustrates the variation of the gas composition of the product before and after purification. Purification consists in eliminating not only the elements traces like the steam, the hydrogen sulfide, the halogenous compounds, but also the carbonic gas, in order to enrich the methane concentration.

According to the results obtained, $\% \mathrm{CH}_{4}$ largely increased by $15 \%$ after purification, whereas $\% \mathrm{CO}_{2}$ and $\% \mathrm{H}_{2} \mathrm{~S}$, on the contrary, decreased the first from almost $5 \%$ and the second of $10 \%$. Let us note that biogas is of as much better than its percentage out of methane is high and than the other components are reduced as much as possible.

Table1. Effect of purification on the composition of produced biogas

\begin{tabular}{|l|l|l|l|}
\hline Composition (\%) & $\mathrm{CH}_{4}$ & $\mathbf{C O}_{2}$ & $\mathrm{H}_{2} \mathrm{~S}$ \\
\hline Before purification & 59.68 & 30.00 & 10.28 \\
\hline After purification & 74.54 & 25.45 & 00.01 \\
\hline
\end{tabular}

The results obtained are indices of the good performance of the process of purification and great importance of the treatment of biogas, since it more ensures a reduction in polluting elements $\left(\mathrm{CO}_{2}\right.$ and $\left.\mathrm{H}_{2} \mathrm{~S}\right)$ as well as an intensification in concentration $\mathrm{CH}_{4}$.

\subsubsection{EFFECT OF PURIFICATION ON THE CALORIFIC VALUE}

The results corresponding to the LCV and $\mathrm{HCV}$ of the biogas produced before and after purification are reported in table 2.

After purification, there is a clear improvement of the calorific value. One can say that industrial biogas produces present valid energy potentialities before and after purification. The energy valorization of biogas can be a relevant source of incomes to amortize the initial investment [20] since biogas is converted into practically all useful shapes of energy [21, 22, 23]. It makes it possible the farm to acquire a fuel autonomy for the production of heat and, if 
the installation comprises an production unit of electricity, to reduce the costs of its purchase and to possibly dispatch the surpluses on the network $[24,25]$.

However, it is advisable to more improve the output of purification of biogas to reach the theoretical maximum equal to $8500 \mathrm{kcal} / \mathrm{Nm}^{3}$ [13].

Table 2. Variation of the $\mathrm{CV}$ of biogas before and after purification

\begin{tabular}{|l|l|l|}
\hline & LCV $\left(\mathrm{kcal} / \mathbf{N m}^{\mathbf{3}}\right)$ & $\mathrm{HCV}\left(\mathrm{kcal} / \mathbf{N m}^{3}\right)$ \\
\hline Before purification & 5110 & 5684 \\
\hline After purification & 6389 & 7106 \\
\hline
\end{tabular}

\subsection{RESULTS OF THE AGRONOMIC FOLLOW-UP}

\subsubsection{BIOTEST OF GERMINATION}

A follow-up of the germination of the chick-pea and bean seeds sown at the same time in the pure forestry compost to test, was carried out during 28 days. The results of follow-up are posted in table 3 .

Table 3. Results of the biotest of germination

\begin{tabular}{|l|l|l|}
\hline Plants-test & Period of germination (days) & \% of germination \\
\hline Chick-pea & 8 & 88 \\
\hline Bean & 12 & 85 \\
\hline
\end{tabular}

It is noted that the biotest carried out gave a high germination higher than $80 \%$ for bean like for chick-pea. In the same way, it is noticed that the two leguminous plants show a better growth of the air part. Therefore, the FC, product with the seedbed can be considered ripe. Good germination indicates that the compost does not contain phenolic substances which can block the germination of the seedlings [26].

The compost can be employed for the production of young seedlings, with, as favors compared to the peat, to produce plants more resistant to pathogenic [27]. The use potential of the composts is promising, but remains strongly dependant on their qualitative aspect.

\subsubsection{FOLLOW-UP OF GERMINATION OF THE SEEDS OF ACACIA}

Figure 5 illustrates the evolution of the percentage of germination of the seedlings of Acacia according to the substrate in the course of time. The cumulated percentages of germination correspond to the averages of two containers per substrate. 
Figure 5 illustrates the results raised of cumulated germination. One can distinguish three phases:

- A phase of latency, necessary to the appearance of the first germinations which is prolonged four days for the various substrates. During this phase, the rate of germination remains weak. The duration of this phase is variable according to the nature of substrate. The SC presents the $\%$ highest of about $30 \%$ towards the end of this phase.

- An appreciably linear phase, corresponding to a fast increase in the rate of germination which evolves proportionally with the number of days. The increase is about $50 \%$ for the three substrates tested.

- A stage representing the final percentage of germination.

By way of comparison between the three substrates, it appears that the rate of germination of substrate SC evolves more quickly than the other substrates. However, the slowest evolution of the rate of germination is observed on the level of substrate SA. The substrate SB has an intermediate behavior.

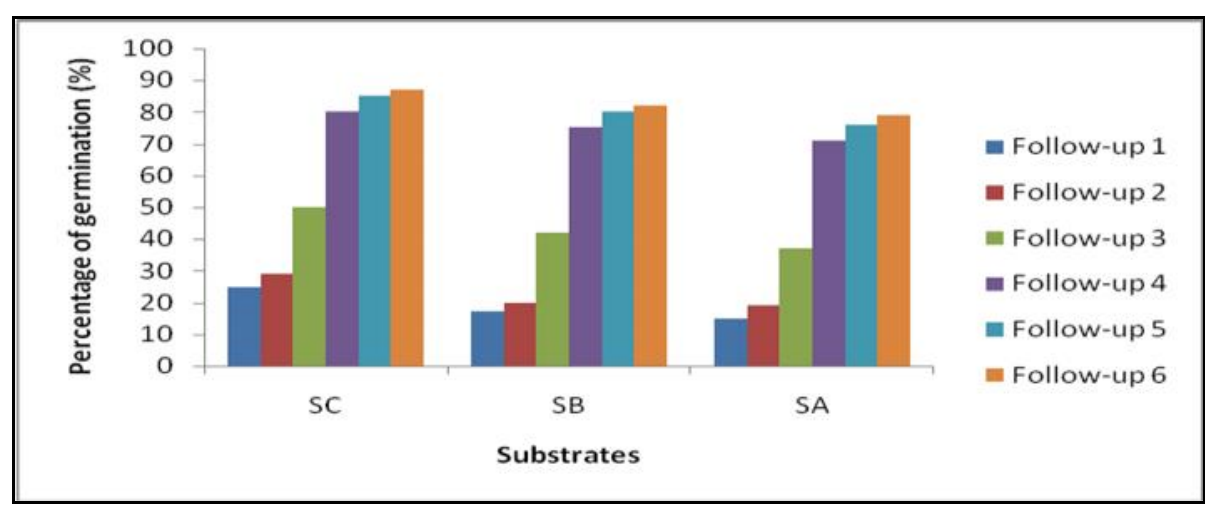

Fig. 5. Variation of the kinetics of germination of seeds of Acacia

\subsubsection{INCREASE IN HEIGHT IN THE SEEDLINGS IN ACACIA}

Figure 6 illustrates the evolution height of the seedlings of Acacia. The results are the averages of measurements in height at a rate of 10 seedlings/substrate $\mathrm{X} 3$ blocks $=30$ seedlings/substrate.

According to [14], the height constitutes a good photosynthetic level indicator and surface of perspiration which are narrowly correlated with the number of the sheets. It seems to predict the growth in height of the seedlings.

Evolution height of the seedlings of Acacia according to the number of days after sowing, watch that the answer of these seedlings with respect to the various substrates is not the same one. The seedlings are sensitive as of the first stages of growth to the nature and the 
composition of the substrate. This sensitivity is generally in keeping with the physicochemical properties of each substrate, in particular its physical quality.

It is noted that the seedlings installed on the FC alone present as of the beginning a delay of growth compared to those installed on the two made mixtures, probably due to a bad contact of seed with the coarse surrounding particles, or to the low richness of the FC in fertilizing elements.

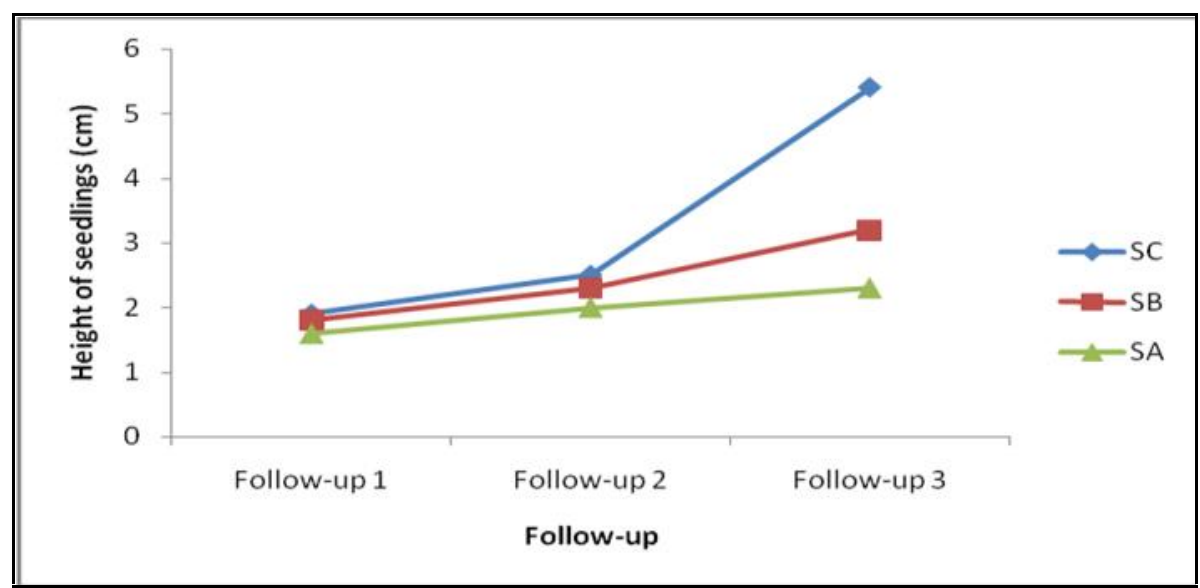

Fig. 6. Variation of the averageheight of the seedlings

\subsubsection{INCREASE IN DIAMETER IN THE SEEDLINGS IN ACACIA}

According to [14], the seedlings having a large diameter generally have well developed side roots. The diameter with the collet is the best parameter of prediction of survival.

The evolution of the diameter of the seedlings of Acacia is illustrated on figure 7 hereafter. This evolution corresponds to the average of 30 specific measures to the diameter for each substrate.

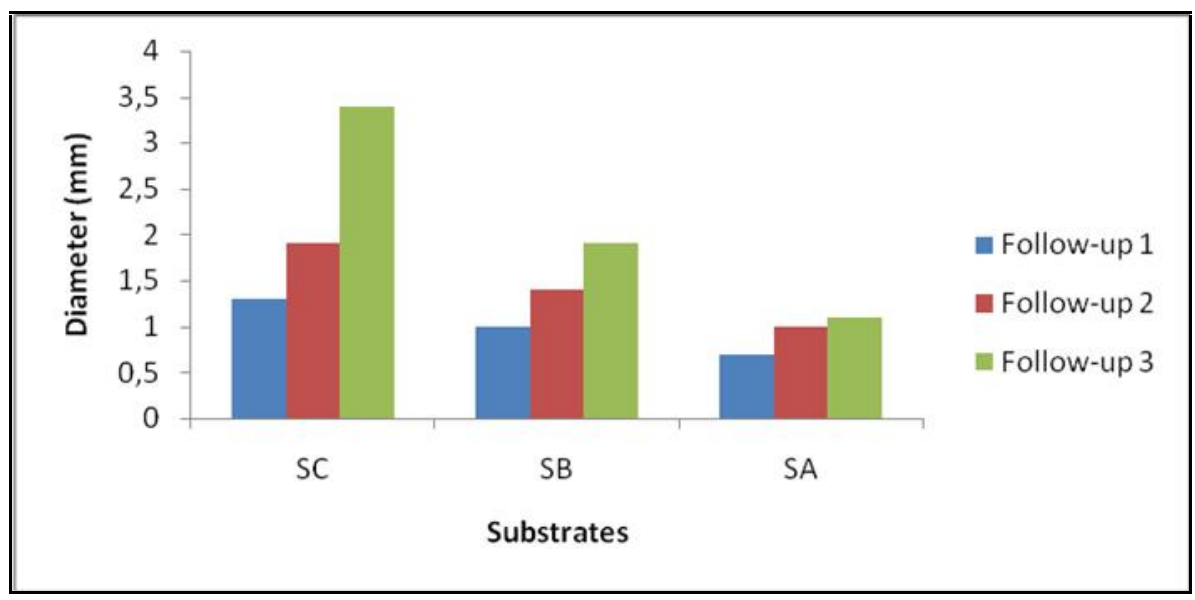

Fig. 7. Variation of the average diameter of seedlings 
Mixture FC and AMCA' presents the most considerable diameter growth of about $3.4 \mathrm{~mm}$. As for the height, the substrate containing mixture FC and AMCA gives median values, whereas the FC comes in last position with largely lower values. One can say that it is about a relation of proportionality between the growth in height and that in diameter.

\subsubsection{RATIO OF ROBUSTNESS}

The results relative to this parameter are represented on figure 8 . The goal of this control is to reach a format of ideal seedling in height, diameter and ratio of robustness. These quality standards are relating not only to morphology but also to the physiology of the seedlings.

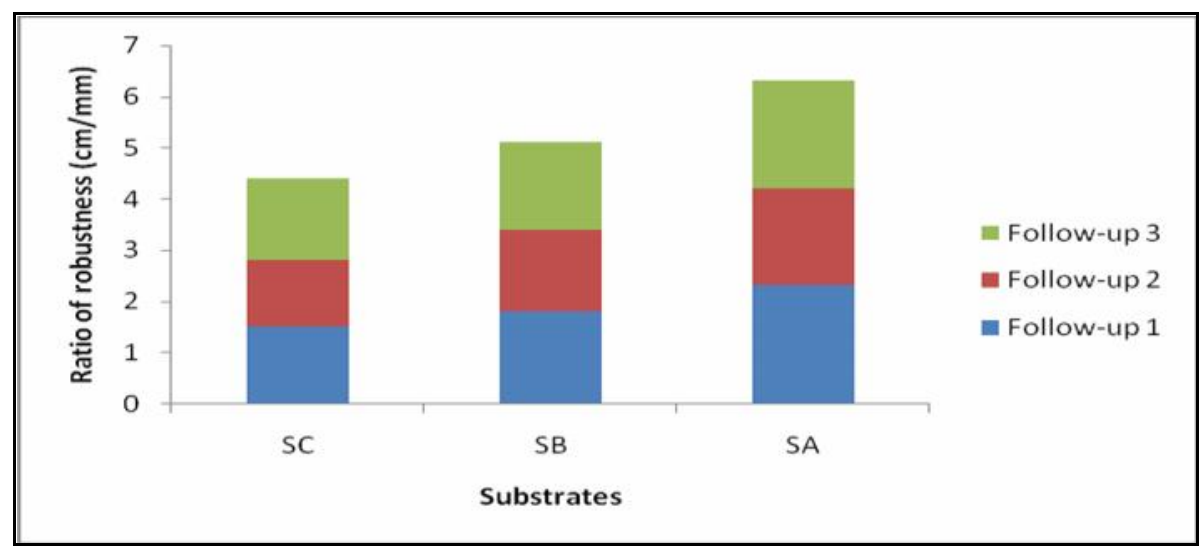

Fig. 8. Variation of the ratio of robustness of seedlings

According to the standards quoted by [14], the ratio of robustness: Height/Diamètre (H/D) expressed in $(\mathrm{cm} / \mathrm{mm})$ should be lower than 7 . So the results are in conformity with the standards. It is noted that the pure FC presents ratios of robustness a little higher than those of the substrates containing mixture. It should be noted that this report cannot be a criterion of characterization of the substrates of growth considering the seedlings of Acacia did not reach along the period of follow-up a advanced developmental stage. Such a result should be raised with prudence.

\section{CONCLUSION}

If the biomethanisation has the merit to be a die of energy production starting from renewable energy sources, its contribution to sustainable development largely exceeds this appreciation. It constitutes a source of diversification for the agricultural world, as it quickly found its place like process of depollution applied to the waste or liquid waste processing. It contributes in a very significant way to the reduction of the emissions of the GES of the agricultural sector particularly methane. As for the energy assessment (relationship between the energy 
contained in the end product and the fossil energy used in its production), it is particularly advantageous when biogas is produced starting from effluents of breeding, since fossil energy to produce biogas is minimal.

The follow-ups environmental and energy, led to the level of the digester pilot industrial in Hammam Sousse (Tunisia), made it possible to justify these two observations on the environmental and energy potentialities of the biogas produced starting from the animal manure and particularly starting from the fresh avicolous droppings.

Starting from various points of the installation presenting, inter alia, the various phases of the process of industrial biomethanisation, an analytical follow-up related to two physicochemical conditions of operation ( $\mathrm{pH}$ and $\mathrm{DM}$ ) since the basin of mixture to decanter. The values obtained always do not respect the standards of normal functioning of such a digester.

This observation is all the more justified by analyzing the results of the follow-up of the environmental parameters ( $\mathrm{SM}$ and $\mathrm{DBO}_{5}$ ). The curves of evolution of these two parameters follow practically the same pattern all the way along process of biomethanisation. The best deduced assessments of depollution are reported with the decanter on the level of which the reduction of the polluting load as of $\mathrm{SM}$ is evaluated to $80.5 \%$ and for the $\mathrm{DBO}_{5}$, it is about $61.6 \%$. The results obtained prove, thus, that the installation strongly contributes to the depollution of the avicolous droppings.

Biogas undergoing a stage of purification which makes it possible more respectively to improve \% methane and the LCV while passing from 60 to $75 \%$ and from 5110 to 6389 $\mathrm{kcal} / \mathrm{Nm}^{3}$.

However, the installation needs some modifications in order to improve its effectiveness as regards environmental and energy performances more, for example the installation of a heating system or in order to improve the financial interest (profitability) of the project by developing the produced quantities of digestats best (methacompost like solid fraction and juice of process like liquid fraction). In this respect, the composting of the vegetable biomass (forestry waste) and the biomethansation of the animal biomass (avicolous droppings) constitute an alternative vis-a-vis the use of the forest or agricultural compost and with the massive imports of the peat.

The study of substitution partial of the forestry compost (substrate of reference) by the avicolous methacompost (on the outlet side of decanter or digester) in the clothes industry of the substrates of growth of the forest seedlings makes it possible to arise the principal results hereafter. 
- The appreciation of the maturity of the FC produced with the seedbed on the leguminous plants (chick-pea and bean) proved a good state of maturation of this compost.

- There exists a light increase in the rate of germination of the seeds of Acacia sown on substrate containing mixture FC and AMCA' that on that containing mixture FC and AMCA. The FC alone shows a rate of germination weaker and rather distant from those obtained for the case of the made mixtures.

- Growth in height and diameter of the seedlings: it was also shown that the growths in height and diameter of the seedlings of Acacia cyanophylla were significantly influenced by the type of the AMCA incorporated with the FC. The mixture containing the AMCA' showed a clear superiority as regards evolution of the seedlings in height and in diameter, on the other hand, the ratios of robustness are overall lower than that of the seedlings cultivated on the CSB (standard substrate).

\section{REFERENCES}

[1] Saidi A., Abada B., 2007. La biométhanisation : une solution pour un développement durable, Revue des Énergies Renouvelables CER'07 Oujda, 31-35.

[2] Tou I., Igoud S., Touzi A., 2001. Production de Biométhane à Partir des Déjections Animales. Rev. Energ. Ren. : Production et Valorisation-Biomasse, 103-108.

[3] Béline F., Gac A., 2007. La méthanisation : un moyen de valoriser la matière organique des déjections animales et de réduire les émissions de gaz à effet de serre. SINFOTECH - Les fiches Savoir-faire, CEMAGREF, 4 p.

[4] Macias-Corral M., Samani Z., Hanson A., Smith G., Funk P., Yu H., Longworth J., 2008. Anaerobic digestion of municipal solid waste and agricultural waste and the effect of co-digestion with dairy cow manure. Bioresource Technology (99), 8288 - 8293.

[5] Schievano A., Pognani M., D’Imporzano G., Adani F., 2008. Predicting anaerobic biogasification potential of ingestates and digestates of a full - scale biogas plant using chemical and biological parameters. Bioresource Technology (99), 8112 - 8117.

[6] Holm-Nielsen J.B., Al Seadi T., Oleskowicz-Popiel P., 2009. The future of anaerobic digestion and biogas utilization. Bioresource Technology (100), 5478-5484.

[7] Moletta R., 1989. Contrôle et conduite des digesteurs anaérobies. Revue des sciences de l'eau (2), 265-293. 
[8] Brondeau P., De La Farge B., Héduit M., 1982. Un nouveau procédé de fermentation méthanique en continu pour les lisiers : Production d'énergie, dépollution et désodorisation. Génie Rural, Janvier-Février (1-2), 5-10.

[9] Angelidaki I., Ellegaard L., 2003. Codigestion of manure and organic wastes in centralized biogas plants. Appl. Biochem. Biotech. (109), 95-105.

[10] Westerman P., Bicudo J., 2005. Management considerations for organic waste use in agriculture. Bioresour. Technol. (96), 215-221.

[11] ALCOR et AXENNE, 2003. Étude stratégique pour le développement des énergies en Tunisie. Bilan des réalisations et Rapport final de l'Agence Nationale des Énergies Renouvelables (ANER), 148-157.

[12] Ramade F., 1993. Dictionnaire encyclopédique de l'écologie et des sciences de l'environnement, Édiscience internationale, Paris.

[13] Monzambe M., 2002. La problématique de la biométhanisation en République démocratique du Congo. Université du Québec, 38 p.

[14] Lamhamedi M.S., Fortinn J.A., Ammari Y., Ben Jalloun S., Poirier M., Fecteau B., Bougacha A., Godin L., 1997. Évaluation des composts, des substrats et de qualité des plants élevés en conteneurs. Rapport technique : Exécution des travaux d'aménagement de trois pépinières pilotes en Tunisie, $112 \mathrm{p}$.

[15] Ammari Y., Lamhamedi M.S., Akrimi N., Zine El Abidine A., 2003. Compostage de la biomasse forestière et son utilisation comme substrat de croissance pour la production de plants en pépinières forestières modernes. Revue de l'I.N.A.T., 99-119.

[16] Bernal M.P., Alburquerque J.A., Moral R., 2009. Composting of animal manures and chemical criteria for compost maturity assessment. Bioresource Technology (100), 54445453.

[17] Juste C., Solda P., Dureau P., 1985. Test agronomique simple destiné à juger rapidement de la phytotoxicité éventuelle et du degré de maturité d'un compost d'ordures ménagères. Comité "Sols et Déchets" 1973-1983. Agence Nationale pour la Récupération et l'Élimination des Déchets, Nantes, 4 p.

[18] Goyal S., Dhull S.K., Kapoor K.K., 2005. Chemical and biological changes during composting of different organic wastes and assessment of compost maturity, Bioresource Technology (96), 1584 - 1591. 
[19] Akrout J., 1992. Étude énergétique de la fermentation méthanique des fientes de volailles: optimisation des facteurs influents et modélisation du système. Doctorat de Spécialité, École Nationale des Ingénieurs de Tunis, 143 p.

[20] Trigui A., 2008. Étude en vue de l'élaboration d'un plan d'action pour l'utilisation énergétique des sous produits de l'oliveraie en Tunisie. PNUD-Tunisie/ ANME (33), 88 p.

[21] Pahl O., Firth A., Mac-Leod I., Baird J., 2008. Anaerobic co-digestion of mechanically biologically treated municipal waste with primary sewage sludge: A feasibility study. Bioresource Technology (99), 3354-3364.

[22] Charles W., Walker L., Cord-Ruwisch R., 2009. Effect of pre-aeration and inoculum on the start-up of batch thermophilic anaerobic digestion of municipal solid waste. Bioresource Technology (100), 2329-2335.

[23] Rao P.V., Saroj Baral S., Dey Ranjan Mutnuri S., 2010. Biogas generation potential by anaerobic digestion for sustainable energy development in India. Renewable and Sustainable Energy Reviews, 2086-2094.

[24] Karellas S., Boukis I., Kontopoulos G. 2010. Development of an investment decision tool for biogas production from agricultural waste. Renewable and Sustainable Energy Reviews (14), 1273-1282.

[25] Poeschl M., Ward Sh., Owende Ph., 2010. Prospects for expanded utilization of biogas in Germany. Renewable and Sustainable Energy Reviews, 14 (7):1782-1797.

[26] Sullivan M., Miller R.O., 2001. Compost quality attributes, measurements, and variability. In: Stoffella, P. J. and Kahn, B. A (Eds.). Compost utilization in horticultural cropping systems. Lewis Publishers, New York, USA, 95-120.

[27] Hoitink H.A.J., Stone A.G., Han D.Y., 1997. Suppression of plant diseases by composts. HortScience 32 (2), 184-187.

\section{How to cite this article:}

M'Sadak Y, Ben M'Barek A. Valorizations environmental, energy and agronomic of biomethanisation industrial of the avicolous biomass. J Fundam Appl Sci. 2015, 7(1), 14-32 